\title{
Desempenho de herbicidas no controle de plantas daninhas em milho silagem
}

\section{Herbicide performance in weed control in corn silage}

\author{
Estéla Philippi ${ }^{1}$, Ricardo Miotto Ternus ${ }^{2}$, Jerffeson Araujo Cavalcante ${ }^{3}$; Alcimar Mazon Fraga ${ }^{4}$
}

\begin{abstract}
Resumo: No estado de Santa Catarina a produção de grãos de milho divide espaço com a produção de milho silagem, sendo está amplamente difundida na pecuária como alimento volumoso para bovinos. Neste sentido, torna-se importante a busca por alternativas que visem minimizar perdas de produtividade, entre elas, reduzir a competição causada por plantas daninhas, que interferem no acúmulo de biomassa. Assim, objetivou-se avaliar a eficiência dos herbicidas Primóleo® (atrazina) e Callisto® (mesotriona) no controle de plantas daninhas na cultura do milho silagem em duas épocas de cultivos. Os ensaios foram arranjados em delineamento experimental de blocos casualizados, em esquema fatorial 4x2 (diferentes tipos de controle e diferentes safras). Os tratamentos foram: aplicações dos herbicidas atrazina e mesotriona, a capina mecânica e a testemunha. Para a aplicação dos mesmos, foi realizado o levantamento da população de plantas daninhas de todas as parcelas com área de 12 metros quadrados cada. Posteriormente, com os tratamentos aplicados, foi efetuado avaliações visuais da eficiência de controle aos 14, 21 e 28 dias após a aplicação, onde o herbicida atrazina se mostrou mais eficiente que o mesotriona, as demais variáveis analisadas foram: produtividade, altura de inserção de espiga e rendimento de espiga. Por meio dessas, verificou-se que controle mecânico de plantas daninhas é mais eficiente que o controle químico, e que não houve diferença significativa de rendimento de milho entre os herbicidas mesotriona e atrazina independentemente da época de cultivo.
\end{abstract}

Palavras-chaves: Zea mays L.; competição; mesotriona; atrazina.

Abstract: In Santa Catarina, the production of grains of maize shares space with the production of corn silage, which is used in cattle as forage for cattle food. In this sense, it is important to search for alternatives that minimize the loss of productivity, among them, reduce competition caused by weeds that affect the biomass accumulation. The objective was to evaluate the efficiency of Primóleo ${ }^{\circledR}$ (atrazine) and Callisto ${ }^{\circledR}$ (mesotrione) herbicides in the control of weeds in corn silage in two seasons of crops. The tests were arranged in a randomized block design, in $4 \times 2$ factorial design (different types of control and different vintages). The treatments were applications of atrazine and mesotrione herbicides, mechanical weeding and the witness. For the application, it was carried out the survey of the population of weed all plots with an area of 12 square meters each. After, with the applied treatments, it was made visual assessments of control efficiency at 14, 21 and 28 days after application, where atrazine was more efficient than the mesotrione. Other variables analyzed were: productivity, ear height and ear yield.Through these, it was found that mechanical weed control is more efficient than chemical control, and no significant difference between maize yield using the mesotrione and atrazine herbicides regardless of the growing season.

Key words: Zea mays L.; competition; mesotrione; atrazine.

\footnotetext{
*Autor para correspondência

Recebido para publicação em 10/12/2015; aprovado em 20/01/2016

${ }^{1}$ Acadêmica do curso de Agronomia, Unibave, Orleans-SC;

${ }^{2}$ Professor do curso de Agronomia, Unibave, Orleans. E-mail: ricardomiter@gmail.com

${ }^{3}$ Mestrando no PPG em C\&T de Sementes, FAEM/UFPel, Pelotas. E-mail: jerffeson_agronomo@hotmail.com

${ }^{4}$ Eng. Agrônomo, Unibave, Orleans. E-mail: alcimarmazon@hotmail.com
} 


\section{INTRODUÇÃO}

Dentre os cereais cultivados no Brasil, o milho é o mais expressivo. Segundo dados da CONAB (2015), esta cultura apresentou cerca de 79,98 milhões de toneladas de grãos produzidos no Brasil, em uma área de aproximadamente 15,16 milhões de hectares, referentes a safra e safrinha do ano de 2014/2015.

Em Santa Catarina, a safra 2012/2013 de milho para grãos, foi caracterizada pelo decréscimo na área plantada, porém não houve redução na produção, e sim, um incremento de $9,86 \%$ em relação à safra anterior. Esse aumento na produção é proveniente da região Oeste do estado, onde se encontra a maior parte da área plantada (EPAGRI, 2014). Com um total de 489 mil hectares plantados, Santa Catarina obteve na safra 2012/2013, produtividade de $6.870 \mathrm{~kg} / \mathrm{ha}$ de grãos (CONAB, 2015).

No entanto, a região Sul do estado, quando comparada as demais regiões, não possui representatividade na produção de milho, principalmente aquele destinado a produção de grãos. Não existem dados específicos, porém, segundo o IBGE (2013), foram cultivados na região Sul de Santa Catarina na safra 2012/2013 pouco mais de 22 mil hectares, com cultivares de milho destinadas para produção de silagem.

Dentre os fatores que influenciam na produtividade da cultura do milho, destaca-se a interferência de plantas daninhas, durante o período de maior vulnerabilidade da cultura (VIDAL et al., 2005; SILVA et al., 2007), sendo necessário alguns cuidados no controle.

O controle químico de plantas daninhas, na cultura do milho, tem se destacado pela eficácia, rendimento operacional e melhor relação custo/benefício. A eficácia de controle é variável e dependente das características físico-químicas do produto, condições edafoclimáticas, época de aplicação e espécies de plantas daninhas a serem controladas (MEROTTO JUNIOR et al., 1997).

Em geral, o controle das plantas daninhas no milho é realizado com herbicidas de pós-emergência, pela flexibilidade da escolha do produto e da dose a serem aplicados para as espécies presentes, e também em função da infestação da área. Nessa modalidade de aplicação a seletividade dos herbicidas é muito importante (VIDAL et al., 2002), junto com a época de aplicação dos herbicidas. Essa varia em função da espécie presente, de sua população e da época que incidem (ZAGONEL et al., 2000), e em geral a cultura deve ser mantida livre da presença das plantas daninhas entre 20 e 45 dias após a emergência (BLANCO et al., 1978).

Duas moléculas vêm sendo bastante utilizadas no controle de plantas daninhas nas lavouras de milho, atrazina (6-chloro- $\mathrm{N}_{2}$-ethyl- $\mathrm{N}_{4}$-isopropyl-1,3,5-triazine-2,4-diamine) e mesotriona [2- (4-mesyl-2-nitrobenzoyl) cyclohexane-1,3dione], sendo ambas classificadas como herbicidas seletivos com aplicação em pós-emergência, utilizados para o controle de plantas dicotiledôneas anuais e poáceas na cultura do milho (FREITAS, 2010; MAPA, 2015).

Diante do exposto, objetivou-se avaliar a eficiência dos herbicidas Primóleo ${ }^{\circledR}$ (atrazina) e Callisto ${ }^{\circledR}$ (mesotriona) no controle de plantas daninhas na cultura do milho silagem em duas épocas de cultivos.

\section{MATERIAL E MÉTODOS}

Foram conduzidos dois experimentos instalados na comunidade de Baixo Pinheiral, de coordenadas $28^{\circ} 13^{\prime} 18^{\prime \prime} \mathrm{S}$ e 49 $06^{\circ}$ ' 25.9" W, zona rural do município de Braço do Norte, Santa Catarina, caracterizado, segundo Köeppen, como clima subtropical úmido ( $\mathrm{Cfa}$ ) com chuvas bem distribuídas e temperatura média anual de $21^{\circ} \mathrm{C}$ (Figura 1), em sistema de cultivo convencional sobre um solo franco arenoso, sendo o mesmo persistindo por duas safras consecutivas 2014/2015 e $2015 / 2015$. Os ensaios foram arranjados em delineamento experimental de blocos completos ao acaso, em esquema fatorial $4 \times 2$ (diferentes tipos de controle e diferentes safras) com quatro tratamentos e cinco repetições, possuindo cada parcela área útil de $12 \mathrm{~m}^{2}$.

Figura 1- Dados meteorológicos das coordenadas $28^{\circ} 13^{\prime} 18^{\prime \prime}$ $\mathrm{S}$ e $49^{\circ} 06^{\prime} 25.9^{\prime} \mathrm{W}$, zona rural do município de Braço do Norte, Santa Catarina no período de outubro de 2014 a maio de 2015. A - Insolação total (horas); B - Precipitação total média $(\mathrm{mm}) ; \mathrm{C}$ - T máxima média $\left({ }^{\circ} \mathrm{C}\right)$; D - T mínima média $\left({ }^{\circ} \mathrm{C}\right)$; E - Umidade Relativa Media (\%).

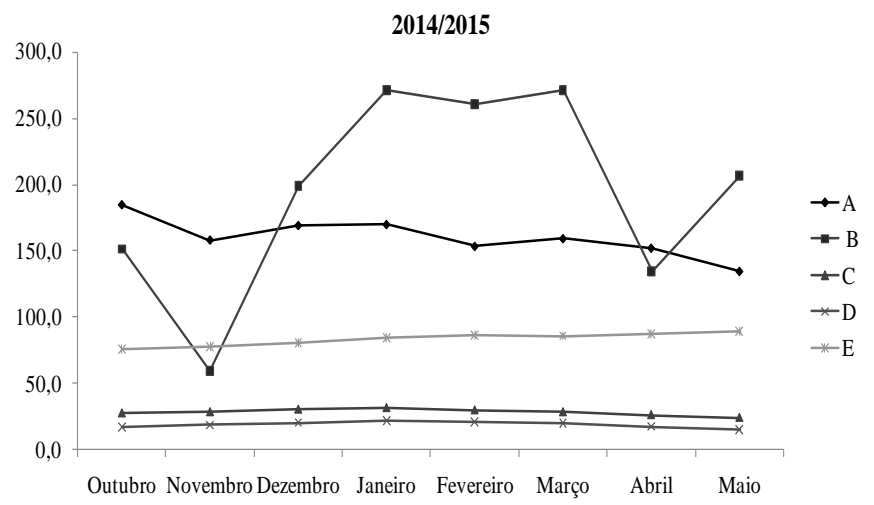

A semeadura foi realizada em fileiras espaçadas de 80 $\mathrm{cm}$, semeando-se de 5 a 6 sementes por metro, a uma profundidade de $5 \mathrm{~cm}$. A cultivar utilizada nas duas safras foi o híbrido triplo AG 8011. A semeadura na primeira safra foi efetuada em 03/10/14 e na segunda safra em 19/02/15. A adubação na primeira safra consistiu da aplicação de $150 \mathrm{~kg}$ $\mathrm{ha}^{-1}$ de adubo químico NPK (05-20-20) na semeadura e $45 \mathrm{~kg}$ $\mathrm{N}$ ha $^{-1}$ de nitrogênio (na forma de uréia), aplicado em cobertura no estádio de 4-6 folhas.

Os tratamentos foram a aplicação em pós-emergência de $6 \mathrm{~L} \mathrm{ha}^{-1}$ de Primóleo® (atrazina); 0,4 $\mathrm{L} \mathrm{ha}^{-1}$ de Callisto ${ }^{\circledR}$ (mesotriona); testemunha capinada e testemunha sem capina. A aplicação dos herbicidas foi realizada com auxílio de um pulverizador costal, com pontas de jato plano "leque" XR 110-02. Aplicou-se o equivalente a $200 \mathrm{~L} \mathrm{ha}^{-1}$ de calda. As aplicações foram realizadas no momento em que a cultura encontrava-se entre os estádios fenológicos (V3-V6), ou seja, apresentando de três a seis folhas em ambas as safras.

As plantas daninhas presentes no experimento, com respectivo número de plantas por metro quadrado e estádio de desenvolvimento, foi avaliado previamente à aplicação dos tratamentos, sendo apresentado na Tabela 1.

A metodologia de avaliação utilizada foi a visual (SBPA, 1995), comparando-se o controle dos herbicidas com 
a testemunha sem capina, onde "0\%" correspondeu a "sem controle" e "100\%" a "controle total". As avaliações de fitotoxicidade foram efetuadas aos 14, 21 e 28 dias após a aplicação (DAA). A colheita na primeira safra foi efetuada no dia 31/01/2015 e em 21/06/2015 foi colhida a segunda safra utilizando-se as plantas da área útil das parcelas. Para determinar a altura de inserção de espiga, foram utilizadas 20 plantas de cada parcela. Já para os índices de produtividade, número de grãos por fileiras e número de grãos por espiga, utilizou-se dez espigas por parcela. Os dados foram submetidos à análise da variância pelo teste $\mathrm{F}$ e as diferenças entre as médias comparadas pelo teste de Tukey $(\mathrm{p}<0,05)$ com o auxílio do programa estatístico Sisvar® (FERREIRA, 1998).

Tabela 1- Identificação (nomes científico e comum), número de plantas $\left(\mathrm{m}^{-2}\right)$ e estádio de desenvolvimento das plantas daninhas presentes na área experimental.

\begin{tabular}{lccc}
\hline & $\boldsymbol{1}^{\boldsymbol{a}}$ Safra (2014/2015) & & \\
\hline Nome cientifico & Nome comum & Número de Plantas & Estádio de desenvolvimento \\
\hline Amaranthus deflexus & Caruru & 27 & 4 a 6 folhas \\
Galinsoga quadriradiata & Picão branco & 14 & 6 a 8 folhas \\
Brachiaria plantaginea & Capim-doce & 6 & 3 a 5 folhas \\
Digitaria bicornis & Milhã & 5 & 2 a 4 folhas \\
Sida rhombifolia & Guanxuma & 3 & 2 a 4 folhas \\
Chamaesyce hirta & Erva-de-santa-luzia & 4 a 6 folhas \\
Lolium multiflorum & Azevém & 2 & 4 a 6 folhas \\
Cynodon dactylon & Grama-de-São-Paulo & 1 & 4 a 6 folhas \\
Eleusine indica & Pé-de-galinha & 1 & 3 a 5 folhas \\
\hline & $\mathbf{2}^{a}$ Safra (2015/2015) & 1 & 2 a 4 folhas \\
\hline Amaranthus deflexus & Caruru & 56 & 2 a 4 folhas \\
Galinsoga quadriradiata & Picão branco & 46 & 3 a 5 folhas \\
Digitaria bicornis & Milhã & 14 & 2 a 4 folhas \\
Chamaesyce hirta & Erva-de-santa-luzia & 12 & 3 a 5 folhas \\
Eleusine indica & Pé-de-galinha & 6 & 3 a 5 folhas \\
Commelina benghalensis & Trapoeraba & 3 & 2 a 4 folhas \\
Bidens pilosa & Picão preto & 2 & 2 a 4 folhas \\
Lolium multiflorum & Azevém & 1 & 2 a 4 folhas \\
Sida rhombifolia & Guanxuma & 1 & 3 a 5 folhas \\
Brachiaria plantaginea & Capim-doce & 1 & \\
\hline
\end{tabular}

\section{RESULTADOS E DISCUSSÃO}

Observa-se na Tabela 2, que o uso do controle mecânico das plantas daninhas apresentou maior eficiência em relação aos herbicidas em ambas as safras. Comparando os controles químicos na safra 2014/2015, o uso da atrazina mostrou-se mais eficiente que o controle com mesotriona. Todavia, na safra 2015/2015 constatou-se que não houve diferença significativa entre as moléculas, sendo que ambas proporcionaram controles superiores a $80 \%$.

Segundo Foloni (2002), trabalhando com o herbicida mesotriona na cultura do milho, observou que esta molécula proporcionou excelentes resultados no controle das plantas daninhas, chegando a controlar de 90 a $100 \%$ Digitaria horizontalis, Eleusine indica, Brachiaria plantaginea, Acanthospermum hispidum, Portulaca oleracea e Galinsoga parviflora. Por outro lado, Fornarolli et al. (1999) verificaram para o tratamento com atrazina na cultura do milho, controle insuficiente, não maior que $55 \%$ para Digitaria horizontalis, Eleusine indica e Brachiaria plantaginea, similar ao obtido na safra 2014/2015.

Destaca-se que a safra 2014/2015 foi conduzida sobre condições climáticas adversas, destacando altas temperatura diurna e a baixa umidade relativa do ar (Figura 1) que podem ter comprometido a eficiência dos herbicidas utilizados, resultando no aumento de população de plantas daninhas na safra 2015/2015 como mostra a Tabela 1, devido ao no banco de sementes resultante no solo.

De acordo Muzik (1976) a umidade relativa do ar, tem grande influência na eficiência de muitos herbicidas aplicados em pós-emergência, pois quanto maior a umidade relativa menor é a quantidade de cera sobre a superfície foliar e menor será a resistência à penetração do produto químico, e mais rápido também será o transporte dos herbicidas.

É importante salientar que, para algumas plantas daninhas, onde nenhum dos tratamentos alcançou $60 \%$ de controle no período avaliado, exceto o controle mecânico, o controle total pode ter ocorrido alguns dias após a última avaliação. Porém, o controle se torna viável quando ocorre dentro do período de maior competição com as plantas daninhas, compreendido entre 20 e 60 dias após a emergência (ZAGONEL et al., 2010). Passado esse período, o controle só se torna importante para que não haja aumento do banco de sementes do solo, pois a competição já trouxe prejuízos para a cultura do milho (DOURADO NETO et al., 2013).

No entanto, a atrazina apresenta mecanismo de seletividade para certas culturas, devido à degradação diferencial, em que nas raízes ou em outras partes ocorre a metabolização e transformação rápida em produtos não tóxicos para as plantas (CARVALHO et al., 2010), tal efeito pode ter comprometido a eficiência desse herbicida para este ensaio. Dourado Neto et al. (2013), trabalhando com diferentes herbicidas e formulação no controle de plantas 
daninhas na cultura do milho, observam que no tratamento em que o mesotriona foi utilizado em associação com atrazina, se conseguiu o melhor efeito na eficiência do controle das plantas daninhas, aos sete dias após a aplicação.

Tabela 2- Eficiência do controle de plantas daninhas (\%) com uso de herbicidas em duas safras de milho silagem.

\begin{tabular}{lccc}
\hline \multirow{2}{*}{ Tratamento } & \multicolumn{2}{c}{ Safra } & \multirow{2}{*}{ Média } \\
\cline { 2 - 3 } & $2014 / 2015$ & $2015 / 2015$ & \\
\hline Testemunha & $6,75 \mathrm{Ad}$ & $1,2 \mathrm{Ac}$ & $3,97 \mathrm{~d}$ \\
Atrazina & $58,75 \mathrm{Bb}$ & $89,2 \mathrm{Ab}$ & $73,97 \mathrm{~b}$ \\
Mesotriona & $32,5 \mathrm{Bc}$ & $85,6 \mathrm{Ab}$ & $59,08 \mathrm{c}$ \\
Controle Mecânico & $96,75 \mathrm{Aa}$ & $98,0 \mathrm{Aa}$ & $97,37 \mathrm{a}$ \\
\hline Média & $48,68 \mathrm{~B}$ & $68,5 \mathrm{~A}$ & \\
\hline CV $(\%)$ & \multicolumn{3}{c}{10,3} \\
\hline
\end{tabular}

Médias seguidas pela mesma letra minúscula na coluna e maiúscula na linha não diferem entre si pelo teste de Tukey a 5\% de probabilidade.

Para a produção de massa verde representado na Tabela 3, constata-se que na safra 2014/2015 o controle mecânico das plantas daninhas proporcionou maior acúmulo de massa verde em relação aos controles químicos, estes por sua vez não diferiram significativamente entre si. Estes resultados correlacionam-se com a eficiência do controle (Tabela 1), como o controle mecânico apresenta maior eficiência, possivelmente, isso proporcionou menor competição interespecífica, acarretando um maior acúmulo de massa verde das plantas.

$\mathrm{Na}$ safra 2015/2015, diferente dos resultados da safra 2014/2015, os controles, mecânico e mesotriona, proporcionaram maior produção de massa verde. No entanto, as plantas submetidas ao controle com mesotriona apresentaram maior acúmulo de massa verde em relação às submetidas ao controle com atrazina (Tabela3).

Observou-se que na safra 2015/2015 o controle mecânico obteve menor produção de massa verde em relação à safra 2014/2015, subentende-se que a maior parte das parcelas com controle mecânico da segunda safra incidiram sobre as parcelas com tratamento correspondente a testemunha da primeira safra, formando assim, um banco maior de sementes de plantas daninhas, acarretando maior competição em pós-emergência. $\mathrm{O}$ mesmo evento se repete em relação ao destaque de produção no tratamento da testemunha na safra 2015/2015, que incidiu a maioria das parcelas sobre o tratamento de controle mecânico da primeira safra, resultando no número reduzido de sementes das plantas daninhas e assim menor as perdas com relação à competição.

Além disso, é possível constatar, independente do controle utilizado, que houve maior acúmulo de massa verde em plantas de milho na safra 2014/2015 em relação à safra 2015/2015 (Tabela 3). Sabe-se que a taxa de crescimento aumenta de acordo com o aumento da temperatura, espera-se que em temperaturas mais elevadas as plantas acumulem mais massa seca do que em temperaturas mais amenas, por ocasião do espigamento (CIRILO; ANDRADE, 1994).

Alfonsi et al. (1997) notaram que, em plantios de milho, estabelecidos em outubro, novembro e dezembro, realizados no Sul do país, o atendimento hídrico é mais provável, fazendo com que as fases fenológicas críticas da cultura do milho (florescimento e enchimento de grãos) coincidam com uma distribuição regular de chuvas.
Por outro lado, Durães et al. (1995) constataram que as condições de cultivo de milho safrinha nos meses de fevereiro, março e abril são desfavoráveis para o desenvolvimento da cultura, principalmente no que tange a produtividade de grãos.

Tabela 3- Produção de massa verde $\left(\mathrm{kg} \mathrm{ha}^{-1}\right)$ em duas safras de milho silagem submetidas ao controle de plantas daninhas com diferentes herbicidas.

\begin{tabular}{lccc}
\hline \multirow{2}{*}{ Tratamento } & \multicolumn{2}{c}{ Safra } & \multirow{2}{*}{ Média } \\
\cline { 2 - 3 } & $2014 / 2015$ & $2015 / 2015$ & \\
\hline Testemunha & $27222,0 \mathrm{Ac}$ & $27291,8 \mathrm{Aa}$ & $27256,9 \mathrm{c}$ \\
Atrazina & $35972,2 \mathrm{Ab}$ & $23125,0 \mathrm{Bb}$ & $29548,6 \mathrm{~b}$ \\
Mesotriona & $34444,2 \mathrm{Ab}$ & $27833,4 \mathrm{Ba}$ & $31138,8 \mathrm{ab}$ \\
Controle Mecânico & $39861,2 \mathrm{Aa}$ & $25826,4 \mathrm{Bab}$ & $32843,8 \mathrm{a}$ \\
\hline Média & $34374,90 \mathrm{~A}$ & $26019,85 \mathrm{~B}$ & \\
\hline CV $(\%)$ & \multicolumn{3}{c}{5,7} \\
\hline
\end{tabular}

Médias seguidas pela mesma letra minúscula na coluna e maiúscula na linha não diferem entre si pelo teste de Tukey a $5 \%$ de probabilidade.

Na Tabela 4, os resultados de altura de inserção de espiga, em ambas as safras, não diferem entre si, porém, a safra 2015/1015 se destaca em um aumento na altura de inserção de espiga proveniente do alongamento de colmo, característica essa devido a condições climáticas, como destaque a redução do fotoperíodo no cultivo de segunda safra (Figura 1).

Tabela 4- Altura de inserção de espiga $(\mathrm{cm})$ em duas safras de milho silagem submetidas ao controle de plantas daninhas com diferentes herbicidas.

\begin{tabular}{lccc}
\hline \multirow{2}{*}{ Tratamento } & \multicolumn{2}{c}{ Safra } & \\
\cline { 2 - 3 } & $2014 / 2015$ & $2015 / 2015$ & Média \\
\hline Testemunha & $64,5 \mathrm{Ba}$ & $100,0 \mathrm{Ab}$ & $82,25 \mathrm{~b}$ \\
Atrazina & $68,76 \mathrm{Ba}$ & $99,26 \mathrm{Ab}$ & $84,01 \mathrm{~b}$ \\
Mesotriona & $63,26 \mathrm{Ba}$ & $122,0 \mathrm{Aa}$ & $92,63 \mathrm{ab}$ \\
Controle Mecânico & $75,26 \mathrm{Ba}$ & $118,0 \mathrm{Aa}$ & $96,63 \mathrm{a}$ \\
\hline Média & $67,94 \mathrm{~B}$ & $109,81 \mathrm{~A}$ \\
\hline CV $(\%)$ & \multicolumn{3}{c}{9,74} \\
\hline
\end{tabular}

Médias seguidas pela mesma letra minúscula na coluna e maiúscula na linha não diferem entre si pelo teste de Tukey a $5 \%$ de probabilidade.

Com relação aos componentes do rendimento número de grãos por fileiras e número de grãos por espiga, não se perceberam diferenças entre os tratamentos, exceto para o controle mecânico em relação aos demais tratamentos (Tabela 5). Porém, elas foram evidentes entre as safras, onde a safra 2014/2015 obteve maiores rendimentos, devido a otimização da radiação e condições edafoclimáticas (Figura 1) melhores no estágio da floração, por consequência da época de semeadura. Segundo Cirilo; Andrade (1994), a temperatura atua de forma inversamente proporcional ao número de grãos definidos por unidade de taxa de crescimento, caracterizando plantios mais precoces (temperaturas mais amenas) como "reprodutivos", em comparação a plantios mais tardios (temperaturas mais elevadas), considerados como "vegetativos". 
Em trabalho realizado por Silva et al. (2004), ao evidenciarem que, além da produtividade, a interferência das plantas daninhas pode influenciar, também, os componentes do rendimento da cultura do milho, fato observado no presente ensaio, já que existe diferença significativa entre a testemunha e o controle mecânico (Tabela 5).

Tabela 5- Produção de massa verde (kg/hectare) em duas safras de milho silagem submetidas ao controle de plantas daninhas com diferentes herbicidas.

\begin{tabular}{|c|c|c|c|}
\hline \multicolumn{4}{|c|}{ Número de grãos por fileira } \\
\hline \multirow{2}{*}{ Tratamento } & \multicolumn{2}{|c|}{ Safra } & \multirow{2}{*}{ Média } \\
\hline & $2014 / 2015$ & $2015 / 2015$ & \\
\hline Testemunha & $36 \mathrm{Ab}$ & $32 \mathrm{Ba}$ & $34 \mathrm{a}$ \\
\hline Atrazina & $36 \mathrm{Ab}$ & $31 \mathrm{Ba}$ & $33 \mathrm{a}$ \\
\hline Mesotriona & $36 \mathrm{Ab}$ & $32 \mathrm{Ba}$ & $34 \mathrm{a}$ \\
\hline Controle Mecânico & 39 Aa & $31 \mathrm{Ba}$ & $35 \mathrm{a}$ \\
\hline Média & $37 \mathrm{~A}$ & $31 \mathrm{~B}$ & \\
\hline $\mathrm{CV}(\%)$ & \multicolumn{2}{|c|}{3,98} & \\
\hline \multicolumn{4}{|c|}{ Número de grãos por espiga } \\
\hline Testemunha & $581 \mathrm{Ab}$ & $487 \mathrm{Ba}$ & $534 \mathrm{a}$ \\
\hline Atrazina & $586 \mathrm{Ab}$ & $491 \mathrm{Ba}$ & $539 \mathrm{a}$ \\
\hline Mesotriona & $574 \mathrm{Ab}$ & $492 \mathrm{Ba}$ & $533 \mathrm{a}$ \\
\hline Controle Mecânico & $637 \mathrm{Aa}$ & $489 \mathrm{Ba}$ & $563 \mathrm{a}$ \\
\hline Média & $595 \mathrm{~A}$ & $490 \mathrm{~B}$ & \\
\hline $\mathrm{CV}(\%)$ & \multicolumn{2}{|c|}{5,16} & \\
\hline
\end{tabular}

Médias seguidas pela mesma letra minúscula na coluna e maiúscula na linha não diferem entre si pelo teste de Tukey a 5\% de probabilidade.

Para Silva et al. (2010) a escolha da época de semeadura é um fator essencial para elevados rendimentos de grãos de milho. A otimização da radiação solar para o sul do Brasil acontece entre meados de setembro ao final de outubro, onde coincidiu o período ideal de floração com os dias mais longos do ano.

\section{CONCLUSÕES}

A matocompetição, juntamente com a ausência de controle, pode ocasionar perdas de até $18 \%$ na produtividade de milho silagem;

O controle mecânico de plantas daninhas em milho silagem é mais eficiente que o controle químico com atrazina e mesotriona;

O herbicida atrazina foi mais eficiente que o herbicida mesotriona;

O controle de plantas daninhas na safra 2014/2015 foi menos eficiente que na safra 2015/2015.

\section{REFERÊNCIAS BIBLIOGRÁFICAS}

ALFONSI, R. R.; VICTORIA FILHO, R.; SENTELHAS, P. C. Épocas de semeadura para a cultura do milho no Estado de SP, baseadas na probabilidade de atendimento hídrico. Revista Brasileira de Agrometeorologia, Santa Maria, v.5, n.1, p. 43-40, 1997.
COMPANHIA NACIONAL DE ABASTECIMENTO. Acompanhamento da safra brasileira de grãos, v. 1, n.1 (2013). Brasília: Conab, 2015.

CIRILO, A. G. E.; ANDRADE, F. H. Sowing date and maize productivity: I. Crop growth and dry matter partitioning. Crop Science, Madison. v.34, p.1039-1043, 1994.

DOURADO NETO, D.; MARTIN, T. N.; CUNHA, V. S.; STECCA, J.; D. L.; NUNES, N. V. Controle de plantas daninhas no milho com o herbicida tembotrione. Enciclopédia Biosfera, Goiânia, v.9, n.17; p.808-817, 2013.

DURÃES, F.O.M.; MAGALHÃES. P.C.; COSTA, J.D.;FANCELLI, A.L. Fatores ecofisiológicos que afetam o comportamento do milho em semeadura tardia ("safrinha") no Brasil central. Scientia Agricola, Piracicaba, v.52, n.2, p.491$591,1995$.

FERREIRA, D. F. Sisvar - sistema de análise de variância para dados balanceados. Lavras: UFLA, 1998. 19 p.

FREITAS I. L. J. Seletividade e eficiência de herbicidas no manejo de plantas daninhas em milho pipoca. Goytacazes: UFRJ, 2010. p.77. (Tese de doutorado)

FOLONI, L. L. Callisto ${ }^{\circledR}$ (mesotrione) - um novo herbicida pós-emergente para a cultura do milho (Zea mays L.). In: Congresso Brasileiro da Ciência das Plantas Daninhas, 23, Gramado, 2002. Anais... SSCPD, p.1-110, 2002.

FORNAROLLI, D.; DONIZETE, A.; BENEDITO, N.; RODRIGUES, D.; VALÉRIO, A. Influência do horário de aplicação no comportamento de atrazine e misturas aplicadas em pós-emergência na cultura do milho. Planta Daninha, Viçosa, v. 17, n.1, p.119-130,1999.

IBGE-INSTITUTO BRASILEIRO DE GEOGRAFIA E ESTATÍSTICA. Censo Agropecuário, 2013. Disponível em: http://www.ibge.gov.br. Acesso em: out/2015.

MAPA, Ministério da Agricultura, Pecuária e Abastecimento. Disponível em:<http://www.agricultura.gov.br >. Acesso em 08 nov. 2015.

MEROTTO JÚNIOR, A. et al. Aumento da população de plantas e uso de herbicidas no controle de plantas daninhas em milho. Planta Daninha, Viçosa, v.15, n.2, p.141-151, 1997.

MUZIK, T.J. Influence of environmental factors on toxicity to plants. In: AUDUS, L.J. Herbicides: physiology, biochemistry and ecology. 2 ed. London. 1976. Academic Press. v. 2, n 7, p. 203-407, 1976.

SILVA, P.R.F. da, et al. Adequação da densidade de semeadura de plantas à épocas de semeadura em milho irrigado. Revista de Ciências Agroveterinárias, Lages, v.9, n. $1, \mathrm{p} 2010$.

SILVA, P. S. L.; MESQUITA, S. S. X.; ANTÔNIO, R. P.; SILVA, P. I. B. Number and time of weeding effects on 
maize grain yield. Revista Brasileira de Milho e Sorgo, Sete Lagoas, v.3, n.2, p.204-213, 2004.

Síntese Anual da Agricultura de Santa Catarina. v.1 1976 2014. Florianópolis: Epagri/Cepa, 1976-Anual.

SOCIEDADE BRASILEIRA DA CIÊNCIA DAS PLANTAS

DANINHAS. Procedimentos para instalação, avaliação e análise de experimentos com herbicidas. Londrina: SBCPD, 1995. $42 \mathrm{p}$.

VIDAL, R.A.; FLECK, N. G.; MEROTTO JR., A. Período anterior ao dano no rendimento econômico: nova abordagem sobre os períodos de interferência entre plantas daninhas e cultivadas. Planta Daninha, Viçosa, v.23, n.3, p.387-396, 2005.

VIDAL, R.A.; SPADER, V.; FLECK, N.G.; MEROTTO JUNIOR, A. Dose de injúria econômica do herbicida cyanazine na cultura do milho. Revista Brasileira de herbicidas, Londrina, v.3, n.2/3, p.127-132, 2002.

ZAGONEL, J.; FERNANDES, E. C.; FERREIRA, C. Períodos de convivência e programa de controle de plantas daninhas em simulação de milho resistente a glifosato. In: Congresso Brasileiro da Ciência das Plantas Daninhas, 27, 2010, Ribeirão Preto. Anais... SSCPD, p.1854-1857, 2010. 